\title{
Lipomatous Pseudohypertrophy of the Pancreas:
}

\section{A Clinicopathologically Distinct Entity}

Deniz Altinel, MD`, Olca Basturk, MD ${ }^{\dagger}$, Juan M. Sarmiento, MD ${ }^{\ddagger}$, Diego Martin, MD§, Michael J. Jacobs, MD\|, David A. Kooby, MD $\ddagger$, and N. Volkan Adsay, MD

*Department of Pathology, Emory University, Atlanta, GA

tDepartment of Pathology, New York University, New York, NY

¥Department of Surgery, Emory University, Atlanta, GA

$\S$ Department of Radiology, Emory University, Atlanta, GA

"Department of General Surgery, Providence Hospital, Southfield, MI

\section{Abstract}

Objectives-Owing to the challenges in obtaining pancreatic biopsies, pancreatic resection for presumed malignancy is often performed without histological confirmation. As a result, benign lesions are sometimes surgically removed. One such condition, which is poorly defined in the literature, is referred to as lipomatous pseudohypertrophy (LPH) of the pancreas.

Methods-Five cases of LPH were analyzed.

Results-Four patients underwent surgical resection, 3 of which were diagnosed preoperatively by radiology as having ductal adenocarcinoma. The fourth case was correctly interpreted by magnetic resonance imaging as LPH, but the patient underwent resection because of the intractable pain due to pancreatitis. The fifth patient has been placed on watchful waiting.

Two tumors were in the pancreatic head, one in the tail, one in the uncinate process, and one demonstrated diffuse involvement. Microscopically, they were characterized as having normal lipocytes without lipoblasts or inflammation. Within the adipose tissue, scattered microscopic foci of pancreatic parenchyma could be seen.

Conclusion-Lipomatous pseudohypertrophy of the pancreas is a distinct entity characterized by localized/diffuse replacement of pancreatic parenchyma with mature adipose tissue. It forms a pseudotumor that may be difficult to distinguish clinically from pancreatic adenocarcinoma. This entity should be considered when evaluating patients with a new diagnosis of a hypodense pancreatic neoplasm on imaging.

\section{Keywords}

lipomatous pseudohypertrophy; pancreas; neoplasm; pseudotumor

Lipomatous pseudohypertrophy (LPH) of the pancreas is a peculiar entity causing enlargement of the pancreas due to a significant increase in adipose tissue in patients who have no obesity or in whom there are no obvious findings of diabetes mellitus or pancreatitis. Examples of this uncommon lesion are reported in the literature as only a 
handful of individual case reports. ${ }^{1-21}$ Associations with rare childhood syndromes such as Shwachman-Diamond, ${ }^{12,19}$ Bannayan, ${ }^{20}$ or Johanson-Blizzard ${ }^{13}$ have been made. Lipomatous pseudohypertrophy often forms a benign mass mimicking cancer, resulting in unnecessary resection and morbidity.

Here, we present 5 new cases and review the clinical and pathological features.

\section{MATERIALS AND METHODS}

In the authors' institutional and consultation files (Wayne State University and Karmanos Cancer Institute, Michigan, 1980-2007; Emory University Hospital, Georgia; Providence Hospital, Southfield, 1999-2007), the pathological materials, including the reports and routine formalin-fixed, paraffin-embedded, and hematoxylin-eosin-stained sections of 2446 cases, were reviewed. Four cases of pancreatic pseudotumor histologically characterized by mature adipose tissue replacing the pancreatic parenchyma were identified, and their clinicopathologic features analyzed. One case diagnosed using magnetic resonance imaging (MRI) scan has been placed on watchful waiting.

Patients' age, sex, tumor size, and the macroscopic findings of the tumors were extracted from the reports (Table 1). Clinical findings of the cases and follow-up data were obtained through contact with the primary physicians or reviews of patients' hospital charts.

\section{RESULTS \\ Clinical Findings}

Mean patient age was 60 years (range, 47-68 years), 3 were female, and 3 cases were identified incidentally on imaging for unrelated concerns, and 2 were symptomatic. One patient presented with a history of chronic pancreatitis and biliary strictures. One was evaluated for new-onset upper abdominal pain. Four patients underwent surgical resection, 3 of which were diagnosed preoperatively as having ductal adenocarcinoma. The fourth case was correctly interpreted using MRI as LPH, but the patient underwent resection because of the intractable pain due to pancreatitis associated with the mass. The fifth patient has been placed on watchful waiting.

Mean patient body mass index (BMI) was $30 \mathrm{~kg} / \mathrm{m}^{2}$ (range, $25-38 \mathrm{~kg} / \mathrm{m}^{2}$ ). There was no history of alcoholism or diabetes mellitus, and none of the patients had evidence of Shwachman-Diamond, Bannayan, or Johanson-Blizzard syndromes.

\section{Pathological Findings}

Macroscopic Findings-In 2 cases, the tumor was located in the head, one was in the tail, and one was in the uncinate process, and there was diffuse involvement of the pancreas in 1 case. The tumors were 24, 13, 7, 2.5, and $2.3 \mathrm{~cm}$ in largest dimension (Table 1). In all cases, there was a sharply demarcated, lobulated, yellow tumor, which is composed of adipose tissue (Fig. 1). In 1 case, part of the common bile duct appeared to be dilated because of the mass effect.

Microscopic Findings-The tumors were composed of mature adipose tissue replacing the pancreatic parenchyma, leaving only scattered clusters of pancreatic elements (Figs. 25), without showing any stigmata of chronic pancreatitis. Pancreatic elements were identified in the remote peripheral edges of the lesions, and in many areas, the tumor was sharply demarcated from the surrounding tissue (Figs. 2 and 3). The acini were extensively replaced by the adipose tissue, with only scattered islets and rare ducts remaining amid the 
fat (Figs. 4 and 5). Lipocytes were entirely normal (Figs. 4 and 5). No lipoblasts were identified. There was no significant inflammation.

One patient (case 2) had an incidental separate serous cystadenoma.

\section{REVIEW OF THE LITERATURE}

When the data reported in the literature ${ }^{1-21}$ are combined with the 5 cases here, the following general characteristics become apparent (Tables 2A and B): mean age is 41 years (range, 6 days to 80 years). There is no distinct difference in the sex distribution (malefemale ratio, 1.2:1). Approximately in $70 \%$ of the cases, there is a diffuse involvement of the pancreas; in 20\%, the tumor is located in the head, and in 10\%, in the body and tail. Most common symptom at presentation is abdominal pain. In some cases, LPH seems to be associated with Shwachman-Diamond, ${ }^{12,19,22}$ Bannayan, ${ }^{20}$ and Johanson-Blizzard ${ }^{13}$ syndromes and juvenile variant of Parkinson disease. ${ }^{10}$ In a few cases, it is reported in conjunction with squamous cell carcinoma, ${ }^{8}$ leiomyosarcoma, ${ }^{23}$ and carcinoma arising in an LPH. ${ }^{14,17}$ Among our patients, one had a separate serous cystadenoma, which is probably of no particular association, because serous cystadenomas are notorious for coexisting with other lesions.

\section{DISCUSSION}

Focal replacement of the exocrine pancreas with mature fat is a common histological change observed in the pancreas. ${ }^{24,25}$ It usually correlates directly with BMI and presence of diabetes mellitus and/or pancreatitis. ${ }^{26-29}$ Lipomatous pseudohypertrophy, by contrast, is the label applied to those cases associated with pseudotumor formation by fat, replacing almost an entire segment of exocrine parenchyma. ${ }^{8}$ Until now, this entity has been documented in the literature mostly by individual case reports ${ }^{1-20}$ (Tables 2A and B).

Lipomatous pseudohypertrophy typically comes to clinical attention incidentally during workup for other conditions, but the tumor is often large (our mean, $9.7 \mathrm{~cm}$ ), up to $24 \mathrm{~cm}$ (as seen in case 4 of our study). Because it forms a mass, it is often mistaken for a malignancy. On the other hand, if proper radiological evaluation is performed, it can be recognized that the lesion is actually composed of fat, as it was in our case 3 . The sheer size of the lesion may be disconcerting in some cases, as seen in one of our patients who received the preoperative diagnosis of liposarcoma. Endoscopic ultrasound-guided, fine-needle aspiration biopsy showing mature fat cells, without any atypia, might be helpful in such cases. ${ }^{30,31}$ Recently, we had another case, a 60-year-old woman who presented with lower abdominal pain, and we diagnosed this patient as having LPH, and the patient is currently on watchful waiting, with no changes in the radiological appearance of the lesion in 3-month intervals at 9 months after the original diagnosis.

Macroscopically, the appearance and consistency are those of adipose tissue. Histological examination of the pancreas shows massive replacement of pancreatic parenchyma by adipose tissue. The islets of Langerhans are relatively preserved, and typically there are scattered, small but well-preserved acinar elements. These acini do not show signs of injury such as cellular attenuation, inspissated secretions or tubular complex formation. No fibrosis or fat necrosis is noted. In other words, these pancreatic elements do not show any signs of either acute or chronic pancreatitis. Most interestingly, the pseudotumor typically has welldefined borders, although it does not appear to have a well-formed capsule. Neighboring pancreatic or soft tissue may show signs of compression; that is, these lesions do appear to have a mass effect. No significant infiltration of inflammatory cells or proliferation of ductal epithelial cells is identified. At the microscopic level, the main differential diagnosis is with 
a well-differentiated liposarcoma, which is reported in the literature as individual case reports. ${ }^{32-35}$ In fact, this was the working diagnosis of the primary pathologist in one of the cases. The findings that speak against this possibility are the perfect maturation of lipocytes, sharp demarcation of the lesion, lack of lipoblasts, and admixture of normal pancreatic parenchyma within the lesion.

The pathogenesis of replacement of the pancreatic tissue by fat is uncertain, and various possible causes have been postulated in the literature. ${ }^{2,4,6,7,9,10,14-16,26,27}$ Hoyer $^{16}$ discussed the possibility of a congenital anomaly, in view of the incidence in childhood, but thought that the condition was more probably acquired, due to injury of the pancreatic parenchyma by infective or toxic agents.

Others have also argued that LPH can be an acquired condition due to obstruction of the ducts and secondary parenchymal damage and atrophy, replaced by adipose tissue. $6,9,14,15$ However, we have not observed any occlusive lesions of the ducts or any inciting factors that may have led to the selective atrophy of the pancreas in our cases. Furthermore, this would not explain the abundance of adipose tissue. Moreover, the scattered pancreatic elements in the lesion appear relatively uninjured.

It has been suggested that LPH may be a form of lipoma. ${ }^{7}$ Pancreatic lipomas are multilobed tumors that are sharply delineated from surrounding pancreatic tissue by a thin fibrous capsule. ${ }^{36-38}$ Lipomatous pseudohypertrophy, on the other hand, is characterized by an enlarged pancreas with massive replacement of pancreatic exocrine tissue by adipose tissue, and the shape of the pancreas is still preserved. ${ }^{6,39}$ More importantly, there are scattered atrophic pancreatic elements within the pseudotumor. Preservation of normal structures can occur in lipomas, such as in intramuscular lipomas; however, the distribution of pancreatic tissue within the lesions in our cases was not in keeping with an entrapment by a tumor, but rather appeared to be an integral part of the process.

In experimental animals, certain toxic agents such as ethionine or viruses have been observed to produce diffuse and massive fat replacement indistinguishable from LPH of the pancreas in humans, unassociated with any obvious inflammatory reaction. ${ }^{4,40}$ Yoshimura et $\mathrm{al}^{10}$ and Sasaki et al ${ }^{2}$ also reported that LPH might be related to chronic hepatitis B or other chronic advanced hepatic lesions that cause a fatty change and Mallory body formation. In fact, one of our patients had a fatty change in the right lobe of the liver, which was demonstrated by MRI. Therefore, the hypothesis that a specific underlying toxic agent may cause LPH of the pancreas may be a plausible explanation but still needs further investigation. On the other hand, relatively well preservation of the pancreatic elements and the pseudotumor formation by the process speak against this possibility.

In conclusion, LPH is a distinct entity of undetermined etiology and pathogenesis. Although some of the cases are easily diagnosed, in some, LPH may present as a pancreatic mass mimicking carcinoma, particularly if it is associated with massive enlargement of the pancreas. Because of mass effect, the lesion might even cause obstructive jaundice. It is important to remember the existence of this entity because it can be quite puzzling for the patients, their family, and the physicians to find out the absence of cancer after a pancreatectomy.

\section{Acknowledgments}

The authors thank Dr Al Braustein from Providence Hospital, Southfield, Mich, for providing 2 of the cases and information on them. The authors also thank Dr Sharon Weiss at Emory University Hospital for providing expert opinion on case 4. 
This study was supported in part by the National Cancer Institute Specialized Program in Research Excellence, P50-CA62924.

\section{References}

1. Kuroda N, Okada M, Toi M, et al. Lipomatous pseudohypertrophy of the pancreas: further evidence of advanced hepatic lesion as the pathogenesis. Pathol Int. 2003; 53(2):98-101. [PubMed: 12588437]

2. Sasaki M, Nakanuma Y, Ando H. Lipomatous pseudohypertrophy of the pancreas in a patient with cirrhosis due to chronic hepatitis B. Pathol Int. 1998; 48(7):566-568. [PubMed: 9701022]

3. Henkinbrant A, Khalek W, Farchakh E, et al. Cholestatic jaundice complicating lipomatous pseudohypertrophy of the pancreas [in French]. Acta Gastroenterol Belg. 1990; 53(3):315-322. [PubMed: 2077797]

4. Siegler DI. Lipomatous pseudohypertrophy of the pancreas associated with chronic pulmonary suppuration in an adult. Postgrad Med J. 1974; 50(579):53-55. [PubMed: 4464502]

5. Flohr T, Bonatti H, Shumaker N, et al. Liver transplantation in a patient with primary sclerosing cholangitis suffering from lipomatous pseudohypertrophy of the pancreas. Transpl Int. 2008; 21(1): 89-91. [PubMed: 17949405]

6. Beresford OD, Owen TK. Lipomatous pseudohypertrophy of the pancreas. J Clin Pathol. 1957; 10(1):63-66. [PubMed: 13406076]

7. Robson HN, Scott GB. Lipomatous pseudohypertrophy of the pancreas. Gastroenterology. 1953; 23(1):74-81. [PubMed: 13021337]

8. Bralet MP, Terris B, Bregeaud L, et al. Squamous cell carcinoma and lipomatous pseudohypertrophy of the pancreas. Virchows Arch. 1999; 434(6):569-572. [PubMed: 10394894]

9. Nakamura M, Katada N, Sakakibara A, et al. Huge lipomatous pseudohypertrophy of the pancreas. Am J Gastroenterol. 1979; 72(2):171-174. [PubMed: 474558]

10. Yoshimura N, Hayashi S, Fukushima Y. Diffuse Mallory bodies in the liver, diffuse Lewy bodies in the brain and diffuse fat replacement (lipomatous pseudohypertrophy) of the pancreas in a patient with juvenile Parkinson's disease. Acta Pathol Jpn. 1992; 42(11):826-831. [PubMed: 1471530]

11. Adsay NV, Basturk O, Klimstra DS, et al. Pancreatic pseudotumors: non-neoplastic solid lesions of the pancreas that clinically mimic pancreas cancer. Semin Diagn Pathol. 2004; 21(4):260-267. [PubMed: 16273945]

12. MacMaster SA, Cummings TM. Computed tomography and ultrasonography findings for an adult with Shwachman syndrome and pancreatic lipomatosis. Can Assoc Radiol J. 1993; 44(4):301-303. [PubMed: 8348362]

13. Maunoury V, Nieuwarts S, Ferri J, et al. Pancreatic lipomatosis revealing Johanson-Blizzard syndrome [in French]. Gastroenterol Clin Biol. 1999; 23(10):1099-1101. [PubMed: 10592887]

14. Salm R. Scirrhous adenocarcinoma arising in a lipomatous pseudohypertrophic pancreas. J Pathol Bacteriol. 1960; 79:47-52. [PubMed: 14441042]

15. Hantelmann W. Fettsucht und Atrophie der Bauch specicheldruse bei Jungendlichen. Virchows Arch. 1931; 282:630-642.

16. Hoyer A. Lipomatous pseudohypertrophy of the pancreas with complete absence of exocrine tissue. J Pathol Bacteriol. 1949; 61:93-100.

17. Salm R. Carcinoma arising in a lipomatous pseudohypertrophic pancreas. Br Med J. 1968; 3(5613):293. [PubMed: 4873662]

18. Schmitz-Moormann P, Pittner PM, Heinze W. Lipomatosis of the pancreas. A morphometrical investigation. Pathol Res Pract. 1981; 173(1-2):45-53. [PubMed: 7335549]

19. Bom EP, van der Sande FM, Tjon RT, et al. Shwachman syndrome: CT and MR diagnosis. J Comput Assist Tomogr. 1993; 17(3):474-476. [PubMed: 8491914]

20. Okumura K, Sasaki Y, Ohyama M, et al. Bannayan syndrome—generalized lipomatosis associated with megalencephaly and macrodactyly. Acta Pathol Jpn. 1986; 36(2):269-277. [PubMed: 3705960] 
21. Lumb G, Beautyman W. Hypoplasia of the exocrine tissue of the pancreas. J Pathol Bacteriol. 1952; 64(4):679-686. [PubMed: 13000582]

22. Belkind-Gerson J, Ontiveros-Nevares P, Ocampo-Roosens V, et al. Shwachman-Diamond syndrome in a Mexican family. Arch Med Res. 2001; 32(4):318-323. [PubMed: 11440791]

23. Shimizu M, Hirokawa M, Matsumoto T, et al. Fatty replacement of the pancreatic body and tail associated with leiomyosarcoma of the pancreatic head. Pathol Int. 1997; 47(9):633-636. [PubMed: 9311016]

24. Stamm BH. Incidence and diagnostic significance of minor pathologic changes in the adult pancreas at autopsy: a systematic study of 112 autopsies in patients without known pancreatic disease. Hum Pathol. 1984; 15(7):677-683. [PubMed: 6745910]

25. Olsen TS. Lipomatosis of the pancreas in autopsy material and its relation to age and overweight. Acta Pathol Microbiol Scand. 1978; 86A(5):367-673.

26. Dupont C, Sellier N, Chochillon C, et al. Pancreatic lipomatosis and duodenal stenosis or atresia in children. J Pediatr. 1989; 115(4):603-605. [PubMed: 2795357]

27. Lozano M, Navarro S, Perez-Ayuso R, et al. Lipomatosis of the pancreas: an unusual cause of massive steatorrhea. Pancreas. 1988; 3(5):580-582. [PubMed: 3186686]

28. Seifert, G. Lipomatous Atrophy and Other Forms. London, UK: Churchill Livingstone; 1984. p. 27-31.

29. So CB, Cooperberg PL, Gibney RG, et al. Sonographic findings in pancreatic lipomatosis. Am J Roentgenol. 1987; 149(1):67-68. [PubMed: 3296712]

30. Suzuki R, Irisawa A, Hikichi T, et al. Pancreatic lipoma diagnosed using EUS-FNA. A case report. J Pancreas. 2009; 10(2):200-203.

31. Di Matteo FM, Shimpi L, Pandolfi M, et al. EUS diagnosis of pancreatic lipoma: a case report. Gastrointest Endosc. 2006; 64(1):146-148. [PubMed: 16813829]

32. Dodo IM, Adamthwaite JA, Jain P, et al. Successful outcome following resection of a pancreatic liposarcoma with solitary metastasis. World J Gastroenterol. 2005; 11(48):7684-7685. [PubMed: 16437699]

33. Milano C, Colombato LA, Fleischer I, et al. Liposarcoma of the pancreas. Report of a clinical case and review of the literature [in Spanish]. Acta Gastroenterol Latinoam. 1988; 18(2):133-138. [PubMed: 3075107]

34. Elliott TE, Albertazzi VJ, Danto LA. Pancreatic liposarcoma: case report with review of retroperitoneal liposarcomas. Cancer. 1980; 45(7):1720-1723. [PubMed: 7370927]

35. Choux R, Andrac L, Rodriguez M, et al. Liposarcoma of the pancreas. Study of a case including ultrastructure [in French]. Ann Anat Pathol. 1979; 24(3):251-259.

36. Bigard MA, Boissel P, Regent D, et al. Intrapancreatic lipoma. First case in the literature. Gastroenterol Clin Biol. 1989; 13(5):505-507. [PubMed: 2753287]

37. Boglino C, Inserra A, Silvano A, et al. Intrapancreatic lipoma: a case report [in Italian]. Pediatr Med Chir. 1993; 15(4):397-399. [PubMed: 8265462]

38. Merli M, Fossati GS, Alessiani M, et al. A rare case of pancreatic lipoma. Hepatogastroenterology. 1996; 43(9):734-736. [PubMed: 8799422]

39. Katz DS, Hines J, Math KR, et al. Using CT to reveal fat-containing abnormalities of the pancreas. Am J Roentgenol. 1999; 172(2):393-396. [PubMed: 9930790]

40. Kojima, K. Current Encyclopedia of Pathology. Vol. 13B. Tokyo, Japan: Nakayama-Shoten; 1983. Metabolic Disturbances of the Pancreas; p. 183-195. 


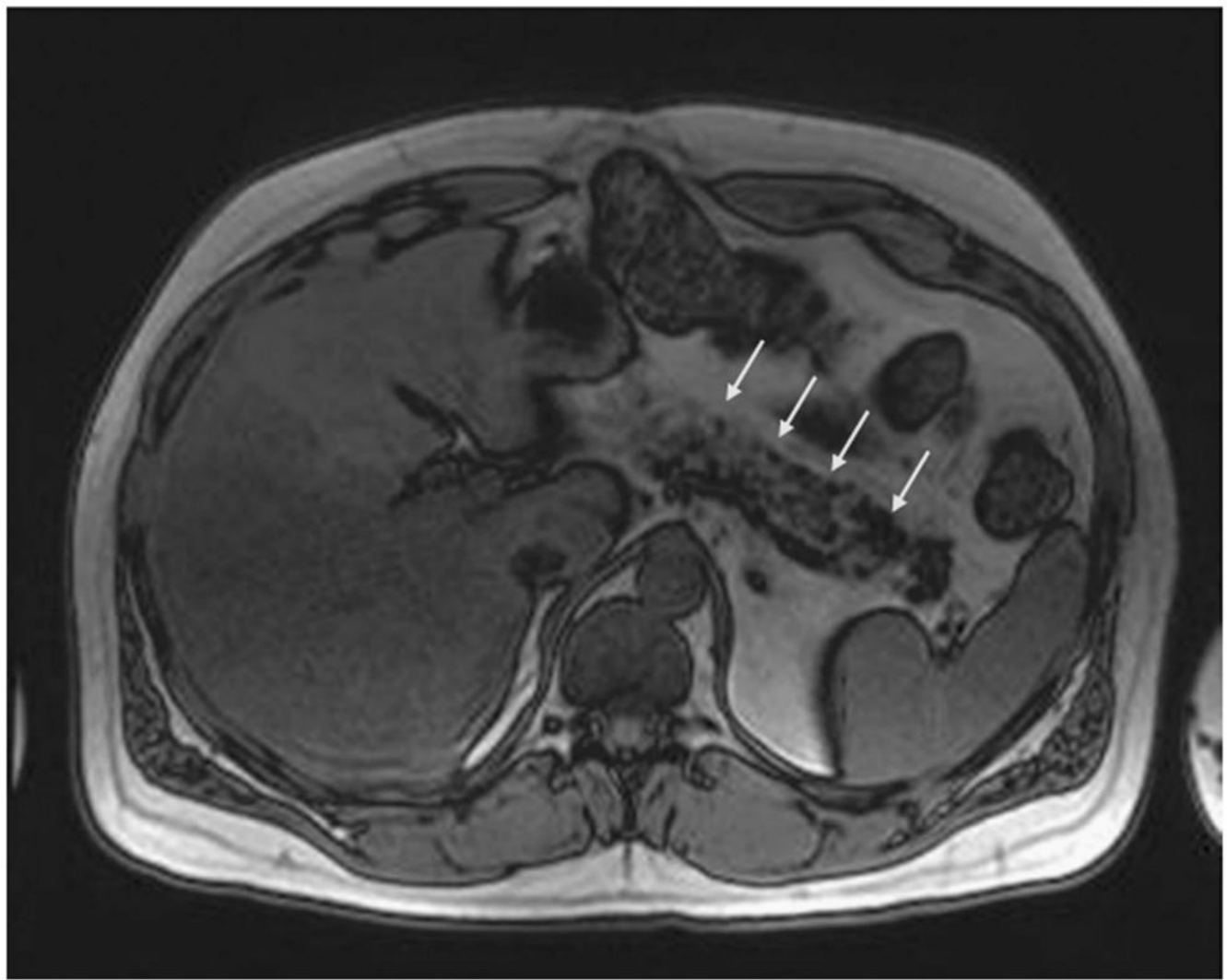

FIGURE 1.

The pancreas is predominantly replaced by fatty tissue. 


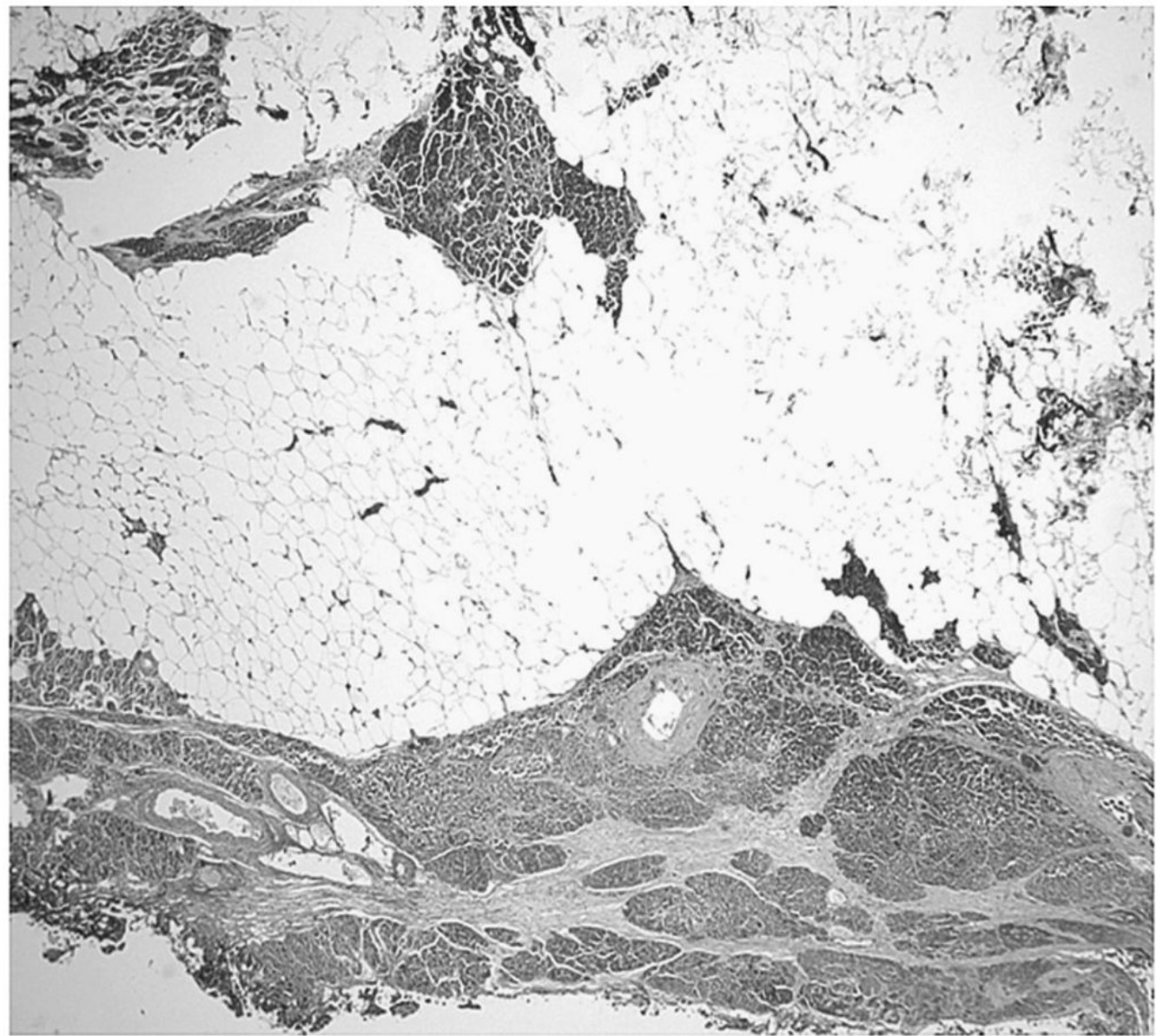

FIGURE 2.

Tumor pushing into the adjacent pancreas is seen. 


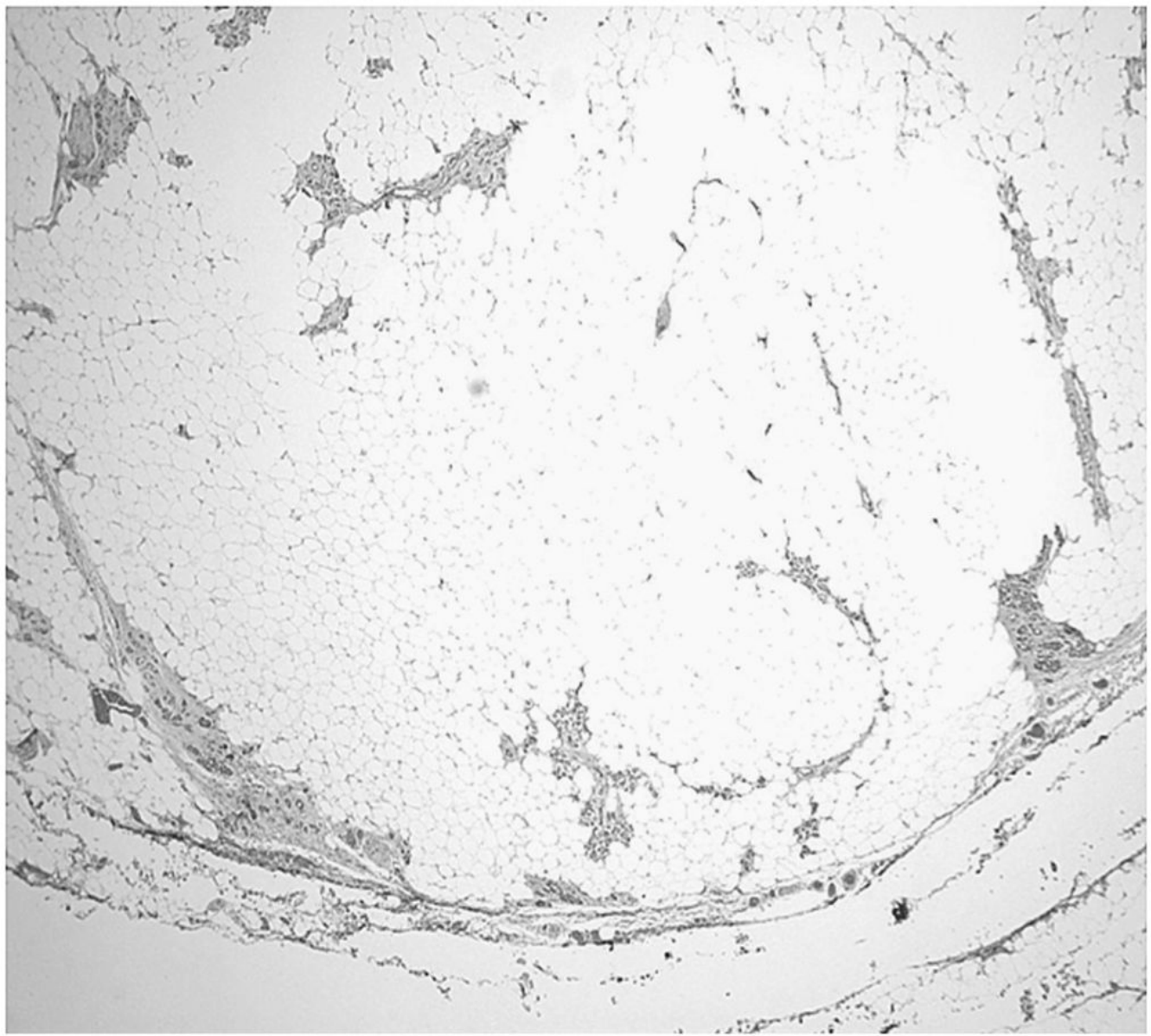

FIGURE 3.

The tumor is well circumscribed, separated from the adjacent normal adipose tissue by a thin rim of fibrous pancreatic tissue. 


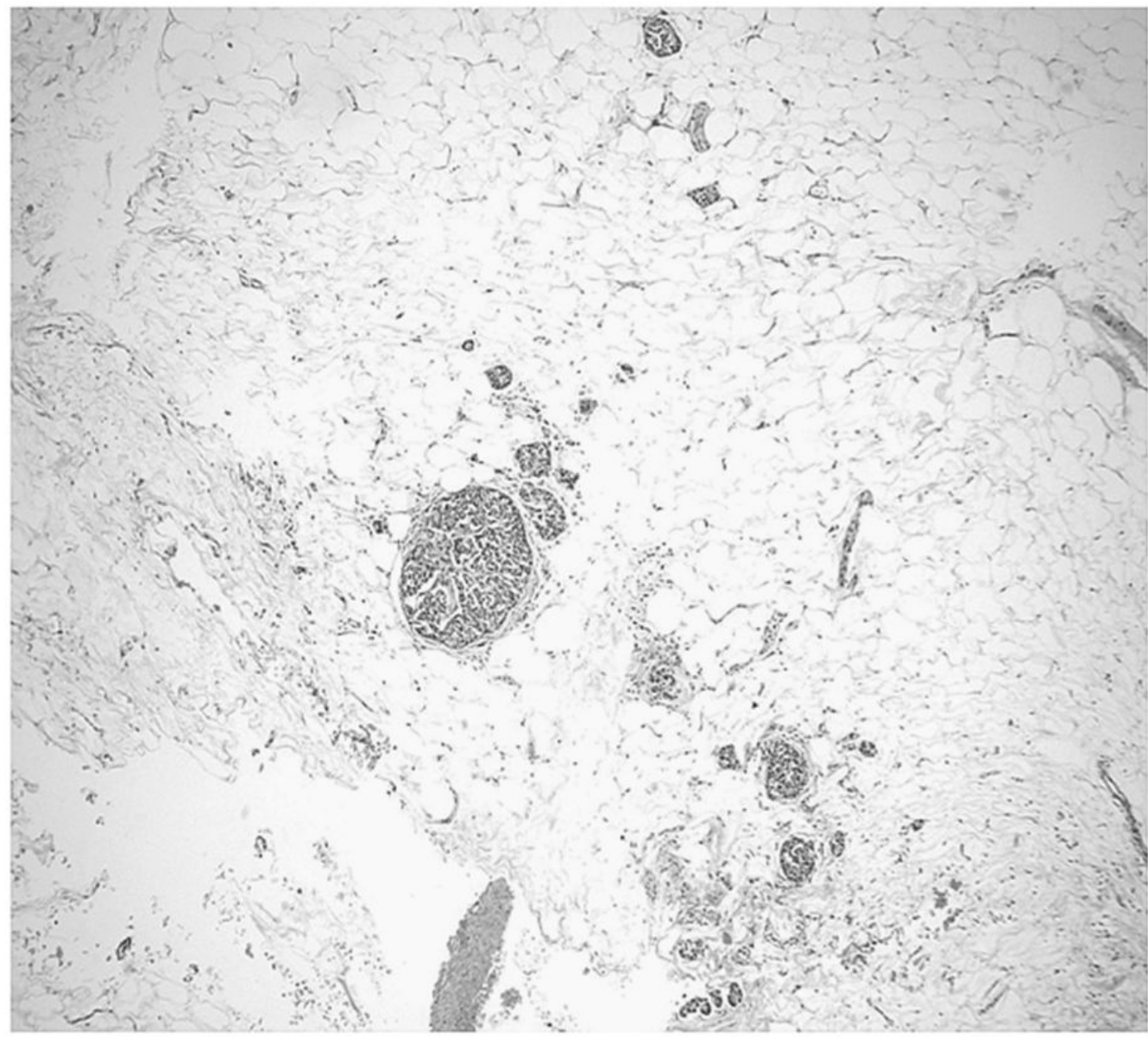

FIGURE 4.

Scattered islets amid the adipose tissue. 


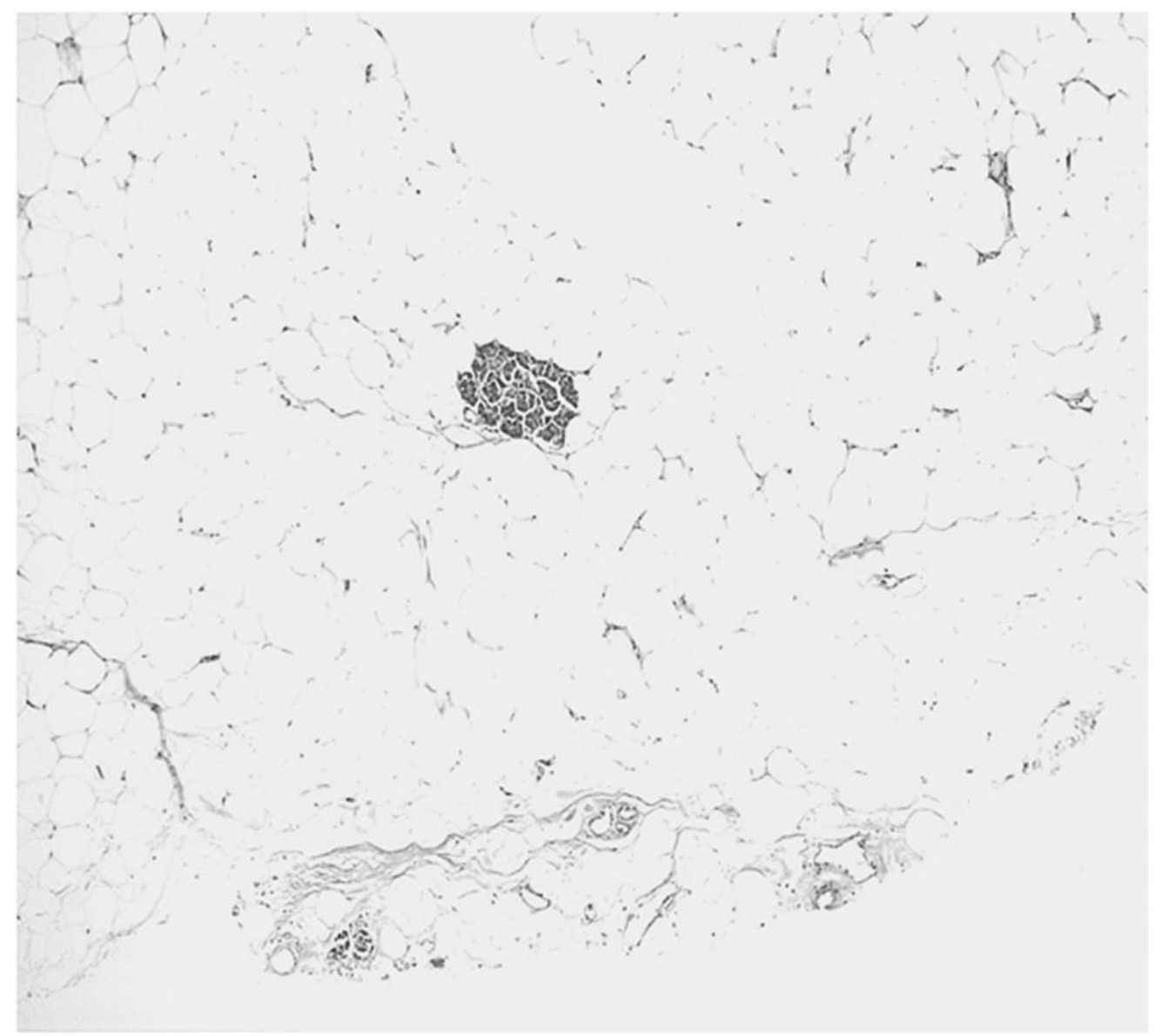

FIGURE 5.

Scattered acini within the adipose tissue. 


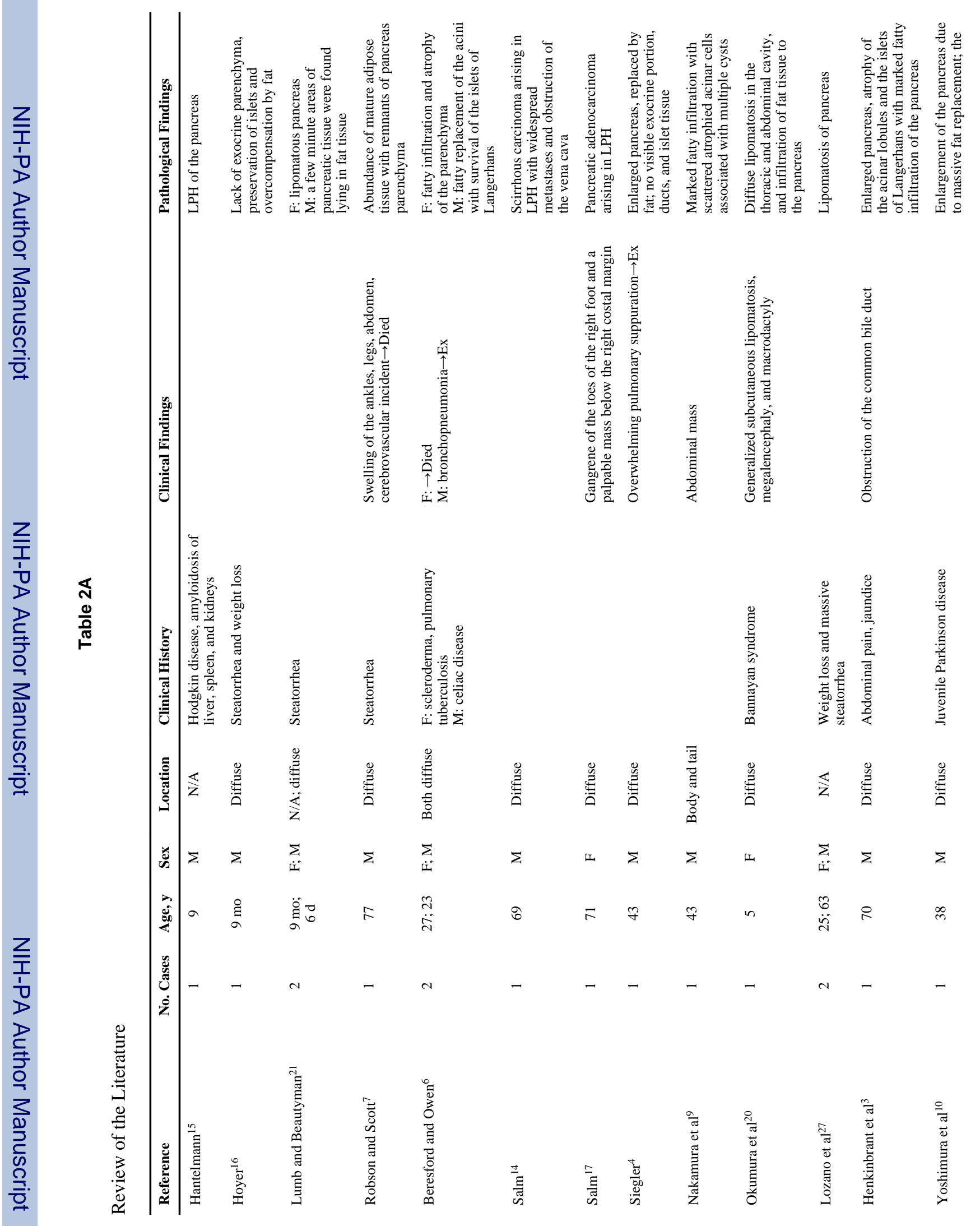


Altinel et al.

Page 14

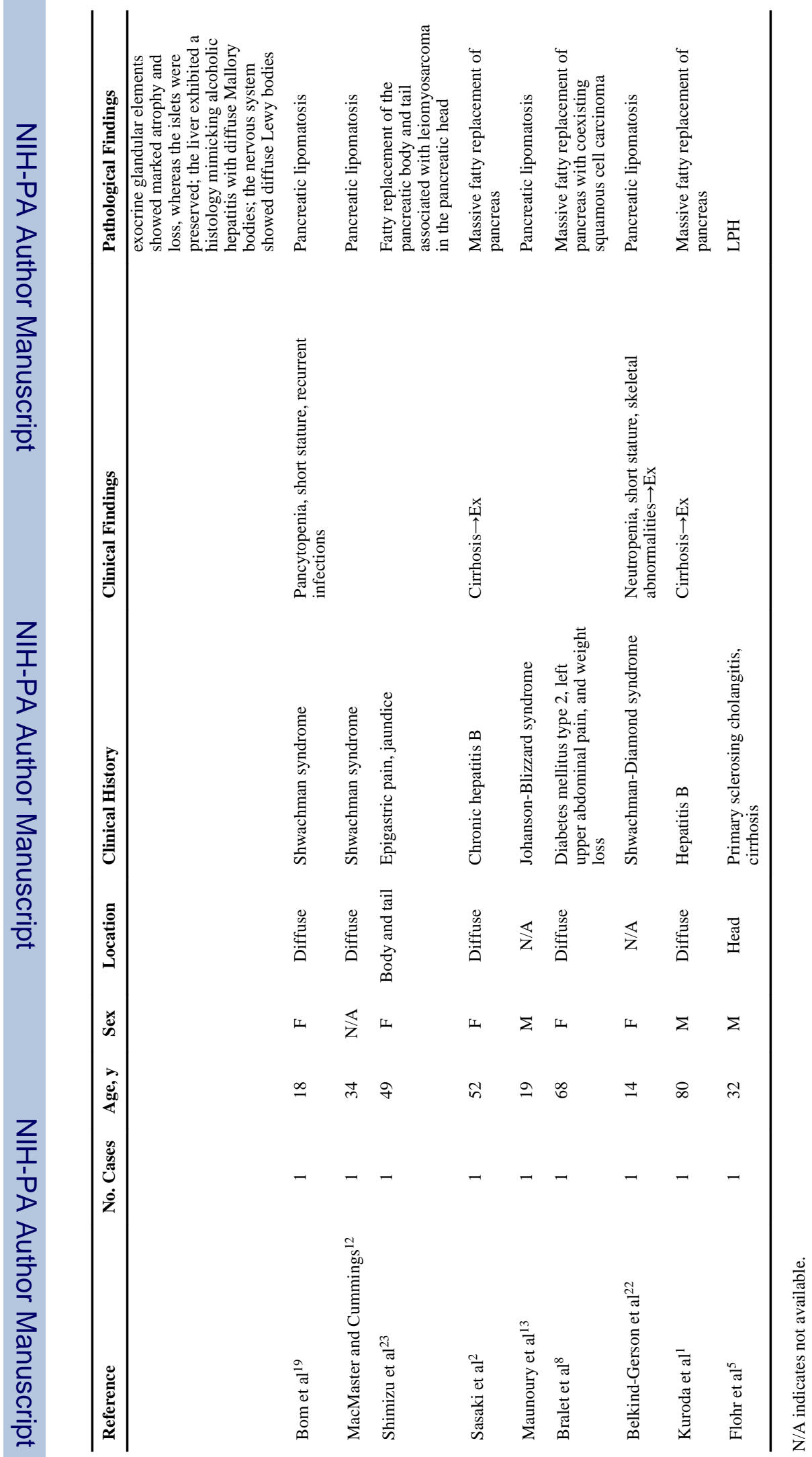

Pancreas. Author manuscript; available in PMC 2011 September 1. 
